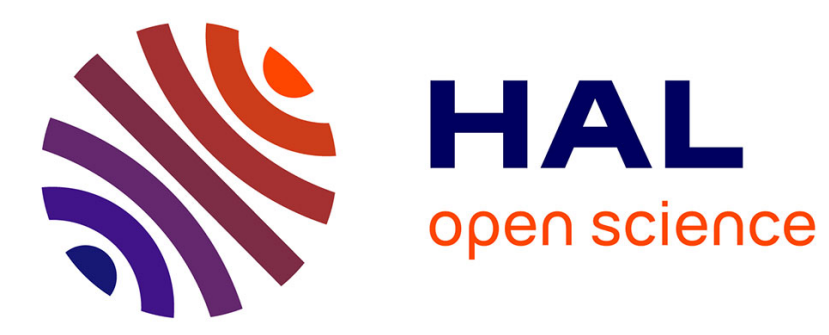

\title{
High Temperature, High Frequency Micro-Inductors for Low Power DC-DC Converters
}

Elias Haddad, Christian Martin, Cyril Buttay, Charles Joubert, Bruno Allard, Dominique Bergogne

\section{- To cite this version:}

Elias Haddad, Christian Martin, Cyril Buttay, Charles Joubert, Bruno Allard, et al.. High Temperature, High Frequency Micro-Inductors for Low Power DC-DC Converters. EPE, Sep 2013, Lille, France. paper 390, 10.1109/EPE.2013.6631994 . hal-00874475

HAL Id: hal-00874475

https://hal.science/hal-00874475

Submitted on 17 Oct 2013

HAL is a multi-disciplinary open access archive for the deposit and dissemination of scientific research documents, whether they are published or not. The documents may come from teaching and research institutions in France or abroad, or from public or private research centers.
L'archive ouverte pluridisciplinaire HAL, est destinée au dépôt et à la diffusion de documents scientifiques de niveau recherche, publiés ou non, émanant des établissements d'enseignement et de recherche français ou étrangers, des laboratoires publics ou privés. 


\title{
High Temperature, High Frequency Micro-Inductors for Low Power DC-DC Converters
}

\author{
E. Haddad, C. Martin, C. Buttay, C. Joubert, B. Allard, D. Bergogne \\ University of Lyon, Ampere Lab, Lyon 1 University, INSA Lyon, UMR5005 \\ 43 Boulevard du 11 novembre 1918 - F-69622 \\ Villeurbanne, France \\ Phone: +33 (0) 472431610 \\ Fax: +33 (0) 472431193 \\ Email: christian.martin@univ-lyon1.fr \\ URL: http://www.ampere-lab.fr/
}

\section{Acknowledgments}

This work is supported by the French National Agency for Research under the project grant Miconet2 $\mathrm{N}^{\circ}$ ANR2010BLAN090904

\section{Keywords}

Magnetic material, high temperature, inductor, electroplating process, passive component integration, high temperature electronics.

\begin{abstract}
The development of micro-inductors is still a challenge to improve the integration level of low power DC-DC converters. The temperature rise due to self-heating or higher ambient temperature represents a risk for system operation. Unfortunately, the use of a heat sink increases the size of the converter and it is more difficult to extract the heat flow dissipated from a smaller area. The increase in the allowable operating temperature offers a solution to achieve a high integration level while ensuring proper heat management. This paper presents the fabrication process of micro-planar inductors with magnetic layers (YIG). The influence of the temperature on the magnetic material and on the inductor performances is studied up to $280{ }^{\circ} \mathrm{C}$. Fabricated micro-inductors are tested using a LCR meter in the $10 \mathrm{kHz}$ to $110 \mathrm{MHz}$ frequency range and over a large temperature range, from $30^{\circ} \mathrm{C}$ to $280{ }^{\circ} \mathrm{C}$.
\end{abstract}

\section{Introduction}

Power converters require the use of passive components, especially inductors. These components occupy a large area and their integration is still a major challenge in low power converters where small and/or low profile systems are expected [1]. It is well known that passive components size depends on the switching frequency of the electrical waveforms. Sufficiently high switching frequency $(>100 \mathrm{MHz})$ enables the decrease in the inductor size to few square millimeters [2]-[3]. It also allows increasing the dynamic response of the converter. Some solutions have been proposed [4] to manufacture such smallsize inductors.

The use of a magnetic material core presents several advantages. In particular, it allows an increase in inductance value compared to a coreless approach. Therefore, a higher inductance value per square millimeter is achieved. ElectroMagnetic Interferences (EMI) are also reduced since the magnetic flux is 
constrained close to the magnetic circuit.

However, proper thermal management becomes critical as the power density increases. Moreover, the properties of the magnetic material are affected by the temperature rise. Thus, it will influence the inductor performances. Therefore it would be useful to design a component with a higher operating temperature capability [5] and to evaluate its performances over a wide temperature range.

This paper is organized as follows: First the fabrication process of the planar inductor is detailed. This process is based on a cost effective electroplating technique, well suited to mass manufacturing. Then, characterizations of the inductor materials (copper and YIG) as a function of the temperature are presented. In the last section, the fabricated inductors are tested and the results are detailed.

\section{Fabrication process}

The fabrication process of the inductor is based on the electroplating of planar copper windings [6].

This technique is well adapted to the deposition of thick copper conductors offering a lower DC resistance and a higher current capability. Electroplating current density can be used to adjust the trade-off between deposition rate and electroplated copper quality. A good trade-off is obtained with a current density fixed at $10 \mathrm{~mA} \cdot \mathrm{cm}^{-2}$. In this condition, the deposition rate reaches $14 \mu \mathrm{m} /$ hour. The test bench is shown in figure 1(a). A pure copper electrode is placed beneath the sample. Both are immersed in the plating bath $\left(\mathrm{CuSO}_{4}-5 \mathrm{H}_{2} \mathrm{O}\right)$. A Source Measure Unit (SMU) is used to adjust the current and voltage between the electrodes. A previous study [7] has shown that placing the electrodes horizontally improves the uniformity of the electroplated copper.

The fabrication process is composed of 8 steps which are briefly described as follows:

- $500 \mu \mathrm{m}$ diameter holes are drilled in a thick $(1 \mathrm{~mm})$ magnetic layer (YIG). These holes line up with the inductor terminals.

- The holes are then filled with copper (figure 1(b)-a) and the excess of copper is polished to achieve a flat surface.

- A seed layer (Ti $50 \mathrm{~nm} / \mathrm{Cu} 150 \mathrm{~nm}$ ) is deposited on the substrate by electron beam evaporation (EBM) (figure 1(b)-b).

- A thick layer (75 $\mu \mathrm{m})$ of dry film photoresist (Dupont Riston PM 275) is then laminated and patterned.

- Copper windings are electroplated using the photoresist film as a mold (figure 1(b)-c). The current density is fixed at $10 \mathrm{~mA} \cdot \mathrm{cm}^{-2}$.

- The dry film is removed with sodium hydroxide $(\mathrm{NaOH})$. The Ti-Cu seed layer is wet-etched to isolate the coil turns with copper etch solution and hydrofluoric acid $(H F)$.

- Finally the copper windings are polished and a thick layer $(100 \mu \mathrm{m})$ bismaleimide film is placed on top of them.

- The last step consists of adding another magnetic layer of YIG material. Then the inductor is compressed at $150{ }^{\circ} \mathrm{C}-2 \mathrm{MPa}$ for 30 minutes to bond both layers of YIG using the bismaleimide film.

Figure 2(a) shows a top view of the inductor without the upper magnetic layer. In figure 2(b), an enlarged cross-sectional image of the copper windings with the two magnetic layers (upper and lower) is presented. It can be observed the bismaleimide film bonding the two magnetic layers and filling the inter-winding spaces. A small air gap is observed between the upper ferrite and the high side copper windings. The inductor occupies an area of $3 \times 4 \mathrm{~mm}^{2}$ in this example. Smaller inductances may be fabricated. Table I summarizes the main geometrical characteristics of this inductor. The materials used in this process will be detailed and characterized in the next section.

Table I: Geometrical characteristics of the inductors considered in this paper

\begin{tabular}{ccccc}
\hline Winding width & Spacing & Copper thickness & Number of turns & Area \\
\hline $75 \mu \mathrm{m}$ & $75 \mu \mathrm{m}$ & $50 \mu \mathrm{m}$ & 5 & $12 \mathrm{~mm}^{2}$ \\
\hline
\end{tabular}




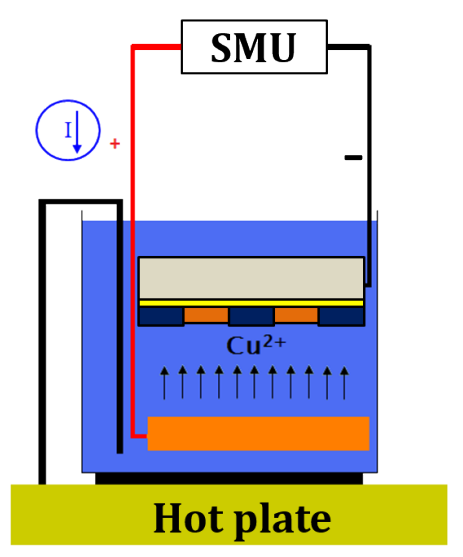

(a) Electroplating test bench

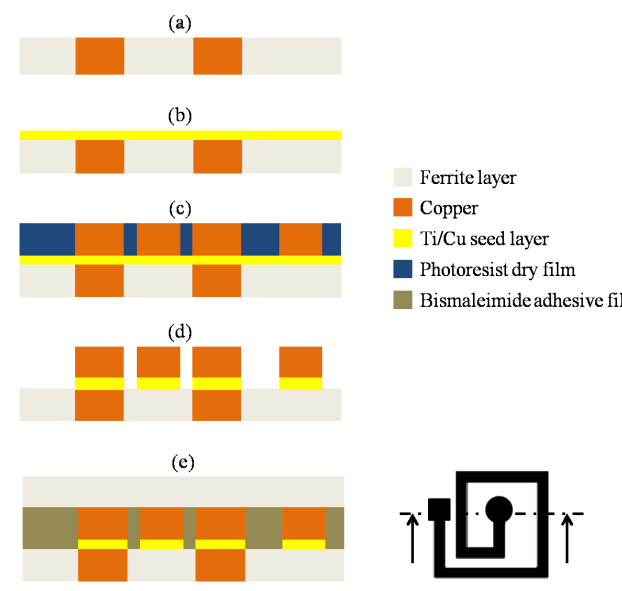

(b) Fabrication process

Figure 1: Description of the inductor fabrication process

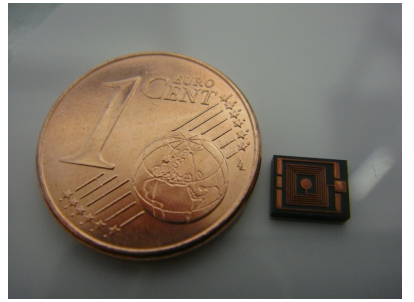

(a) Top view of the windings

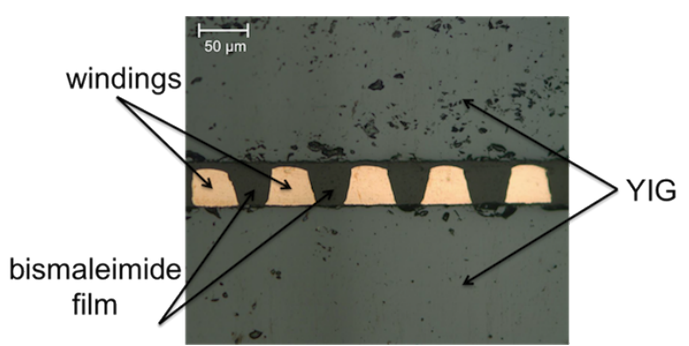

(b) Cross-sectional image of the copper windings

Figure 2: Photos of the fabricated samples

\section{Materials characteristics}

\section{Conductors materials}

The electrical and magnetic performances of the inductor are mainly influenced by the behavior of the materials used during the fabrication process. Table II shows the main characteristics of both metals used for conductors (copper and titanium). We can observe that their melting temperature is far above the targeted operating temperature. Under such conditions and even if resistance increases with temperature, windings can be used up to $200{ }^{\circ} \mathrm{C}$. Thermo-mechanical stress may be forecast but the issue is out of the scope of this paper.

The resistivity of electroplated copper is computed from conductor resistance measurements. An Agilent B1505A analyzer is used to perform these measurements. A dedicated pattern is processed as depicted in figure. 3. Electroplated copper resistivity is evaluated at $2 \cdot 04 \cdot 10^{-8} \Omega . \mathrm{m}$ which seems in good agreement with literature (Table II). It indicates the good quality of the electroplated copper compared to pure copper.

Table II: Characteristics of conductors [8]

\begin{tabular}{ccc}
\hline & Resistivity $: \rho(\Omega . \mathrm{m})$ & Melting temperature $: T_{M}\left({ }^{\circ} \mathrm{C}\right)$ \\
\hline Pure copper & $1.68 .10^{-8}$ & 1084 \\
Titanium & $4.20 .10^{-7}$ & 1668 \\
\hline
\end{tabular}



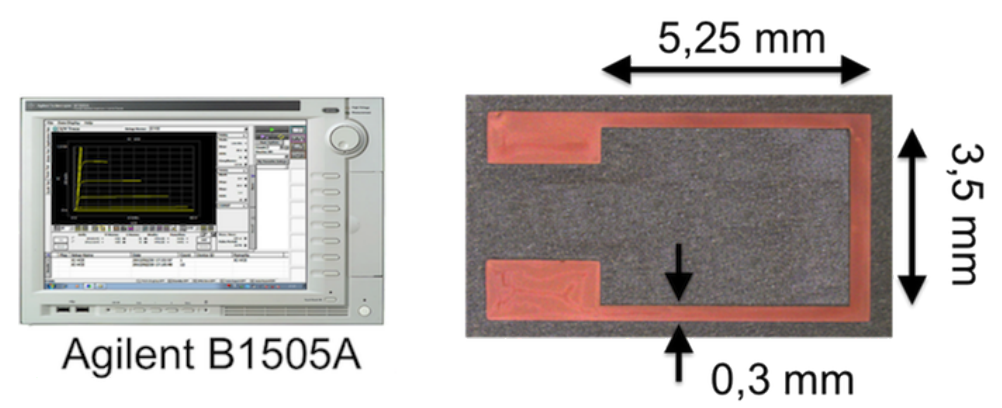

Figure 3: Resistivity measurement of the electroplated copper

\section{Magnetic material}

The magnetic properties of magnetic materials change as the temperature increases [9]. Moreover the magnetic material plays an important role in the performance of the inductor. Any change in its properties modifies the performance of the inductor. In our application, a microwave ferrite magnetic material, YIG (Yittrium Iron Garnet) is used [10]. The geometrical characteristics of the toroidal core used are presented in table III. Both hysteresis loop and complex permeability are studied below.

Table III: Geometrical characteristics of the magnetic core

\begin{tabular}{ccccc}
\hline Inner diameter & Outer diameter & Thickness & $\begin{array}{c}\text { Core cross section } \\
(S)\end{array}$ & $\begin{array}{c}\text { Effective magnetic path } \\
\text { length }\left(L_{\text {avg }}\right)\end{array}$ \\
\hline $8.9 \mathrm{~mm}$ & $14.9 \mathrm{~mm}$ & $1 \mathrm{~mm}$ & $3 \mathrm{~mm}^{2}$ & $37.4 \mathrm{~mm}$ \\
\hline
\end{tabular}

\section{- Hysteresis loop measurements}

The saturation flux density of YIG is evaluated. Figure 4(a) describes the test bench used to plot B-H loops from $30{ }^{\circ} \mathrm{C}$ to $275{ }^{\circ} \mathrm{C}$. A wound-toroidal core of YIG is placed in a forced-convection oven. The magnetic flux density (B) and the magnetic field $(\mathrm{H})$ are computed measuring the current in the primary side and the corresponding induced voltage on the secondary side as follows :

$$
H(t)=\frac{N_{1}}{L_{\text {avg }}} \cdot i_{1}(t) \quad B(t)=\frac{1}{S \cdot N_{2}} \cdot \int v_{2}(t) \cdot d t
$$

$N_{1}$ and $N_{2}$ are the number of turns on the primary and secondary side respectively. $L_{\text {avg }}$ and $S$ are the effective magnetic path length and the cross-section of the core respectively.

Results are illustrated in figure 4(b). Starting at $0.25 \mathrm{~T}$ at $25{ }^{\circ} \mathrm{C}$, the saturation flux density drops to $0.15 \mathrm{~T}$ at $200{ }^{\circ} \mathrm{C}$ and the Curie temperature is estimated at $275^{\circ} \mathrm{C}$. Despite the saturation flux density decrease, a magnetic behavior is still observed. This change must be taken into account in the inductor design in order to avoid the saturation of the magnetic core.

- Complex permeability measurements

Complex permeability is computed from measured impedance values $\left(Z_{S}\right)$ as depicted in equation 2 . An HP4294A impedance analyzer is used to perform these measurements. Geometric characteristics of the core are presented in table III.

$$
\mu_{\text {complex }}=-j \cdot \frac{Z_{S} \cdot L_{\text {avg }}}{\mu_{0} \cdot \omega \cdot N^{2} \cdot S}
$$

The complex permeability is measured at ambient temperature with a dedicated magnetic material test fixture (ref. Agilent 16454A). Results obtained at $25^{\circ} \mathrm{C}$ are shown in figure 5(a). The real part of 


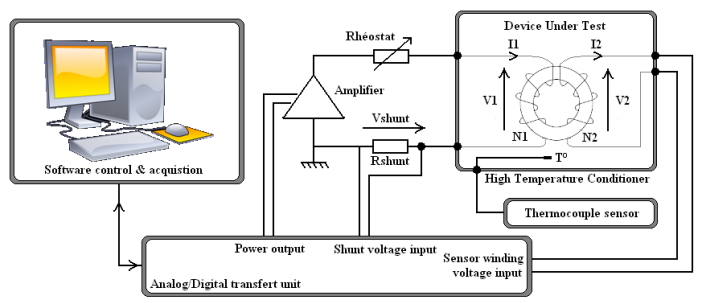

(a) Test bench for B-H loop measurements

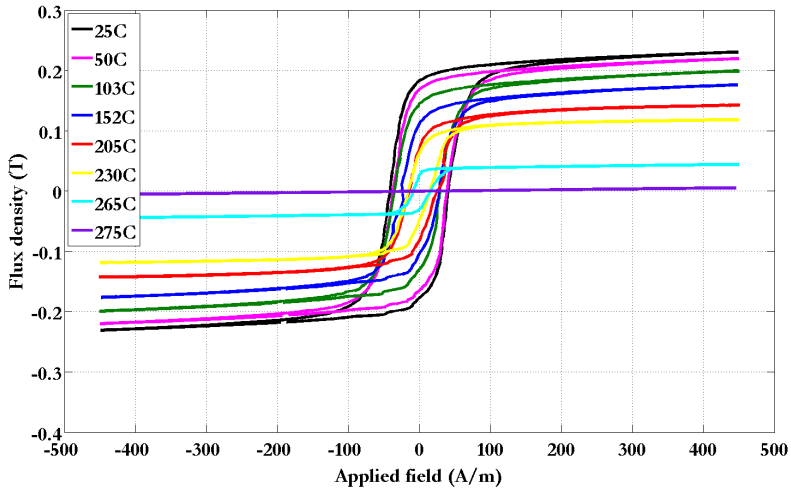

(b) Major hysteresis loops from $25^{\circ} \mathrm{C}$ to $275{ }^{\circ} \mathrm{C}$. Sinusoidal excitation field is imposed at $10 \mathrm{kHz}$

Figure 4: B-H loop experimental characterization

the complex permeability, $\mu^{\prime}$, is used as a reference measurement to validate the characterization test bench dedicated to temperature analysis (described below). $\mu$ ' is quite constant and is equal to 150 in the $10 \mathrm{kHz}$ to $3 \mathrm{MHz}$ frequency range. Despite a permeability decrease above $3 \mathrm{MHz}, \mu$ maintains a significant value up to $100 \mathrm{MHz}$. It is concluded that this magnetic material (YIG) retains its magnetic properties over a large frequency range.

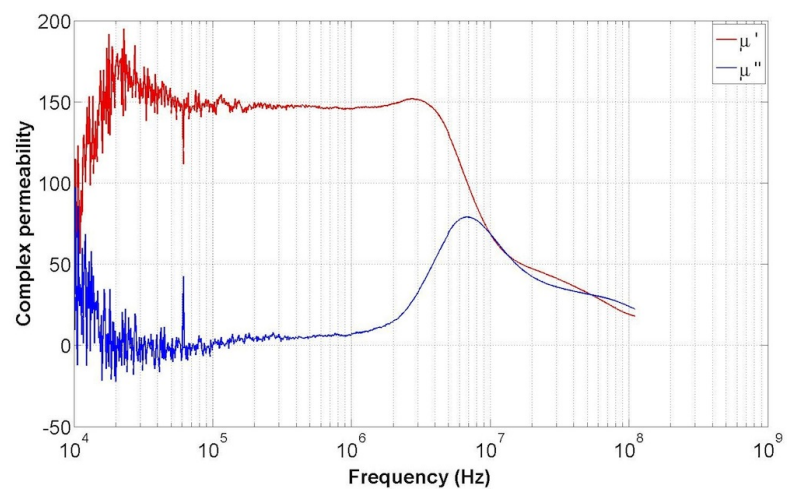

(a)

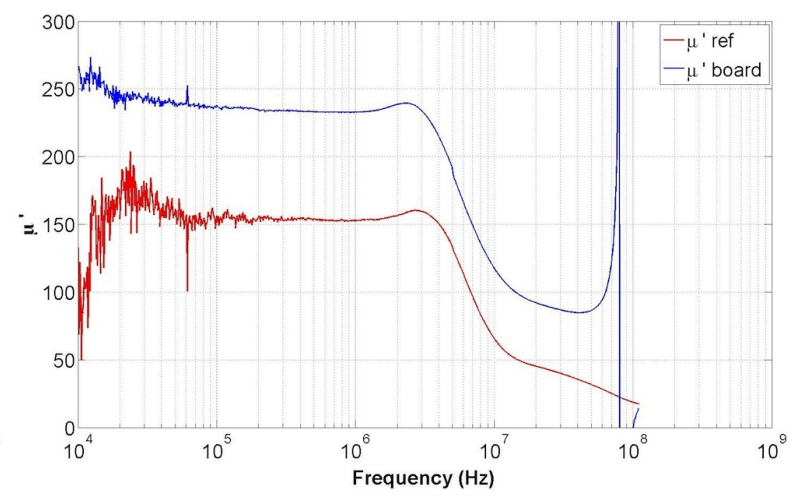

(b)

Figure 5: (a) Permeability characterization with the 16454A test fixture and (b) comparison between the $\mu$ ' value measured with the 16454A and high temperature test board

In order to evaluate the permeability change with temperature, the dedicated magnetic test fixture (16454A) is substituted by a high temperature test board. This board is composed by a high temperature printed copper board, windings and SMA connectors as shown in figure 6(a). Magnetic core is heated up using a hot air flow as shown in figure 6(a). The SMA connector is maintained at room temperature and connected to the impedance analyzer. A K-type thermocouple is used to measure the core temperature. Test fixture setup is performed in order to take into account the test board parasitics. This compensation procedure is achieved using identical circuits with open and short-circuit configurations without magnetic core (figure 6(b)).

Figure 5(b) shows the comparison between the permeability computed with this test bench at $25^{\circ} \mathrm{C}$ and the one obtained previously with the $16454 \mathrm{~A}$ test fixture. It is difficult to measure the real part of the permeability of this material because this value is quite low. It implies that the impedance of the device under test (core and windings) is comparable to the board parasitics. It could explain why a difference can be noted in the real part of the permeability in figure 5(b). However, the behavior of the permeability 


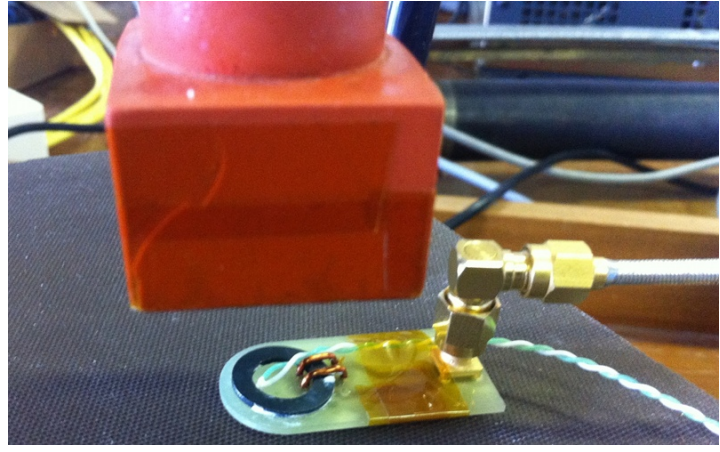

(a)

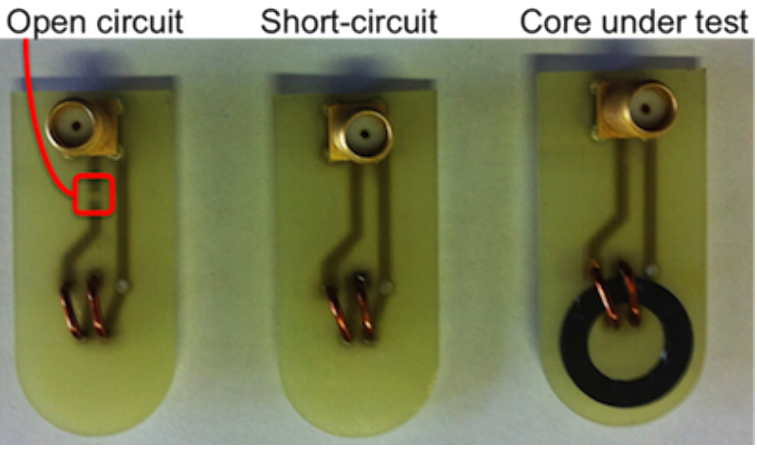

(b)

Figure 6: Test board for permeability characterization as function of temperature

is well represented up to $40 \mathrm{MHz}$. In both cases, the real part of the permeability is quite constant up to $3 \mathrm{MHz}$ and decreases afterwards. It is concluded that this board can be used to evaluate the temperature effect on the permeability change.

Figure 7(a) shows the temperature dependance of the real part of the complex permeability $\left(\mu^{\prime}\right)$. At low frequency, we can observe an increase in $\mu$ ' up to $230^{\circ} \mathrm{C}$, followed by a drop. Figure 7 (b) shows the variation of the permeability with temperature at $100 \mathrm{kHz} . \mu_{R}$ ' quadruples in the $20^{\circ} \mathrm{C}$ to $230{ }^{\circ} \mathrm{C}$ temperature range. A significant decrease is observed beyond $230{ }^{\circ} \mathrm{C}$. Then it reaches 54 at $260{ }^{\circ} \mathrm{C}$. Regarding figure 7(b), Curie temperature can be estimated nearly to $270{ }^{\circ} \mathrm{C}$.

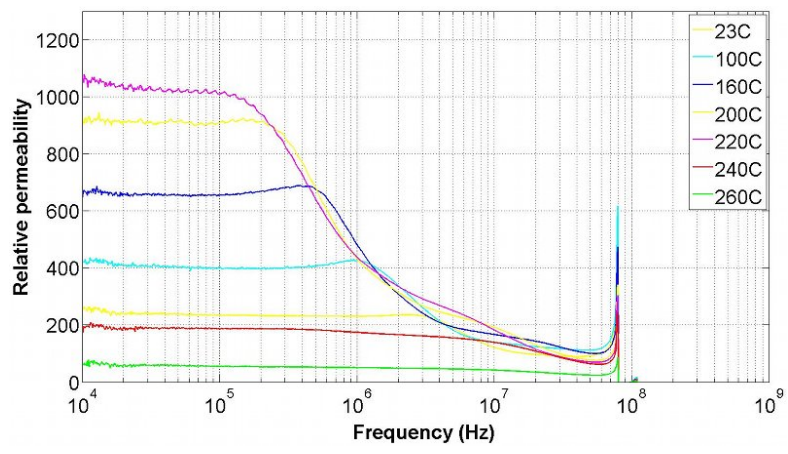

(a)

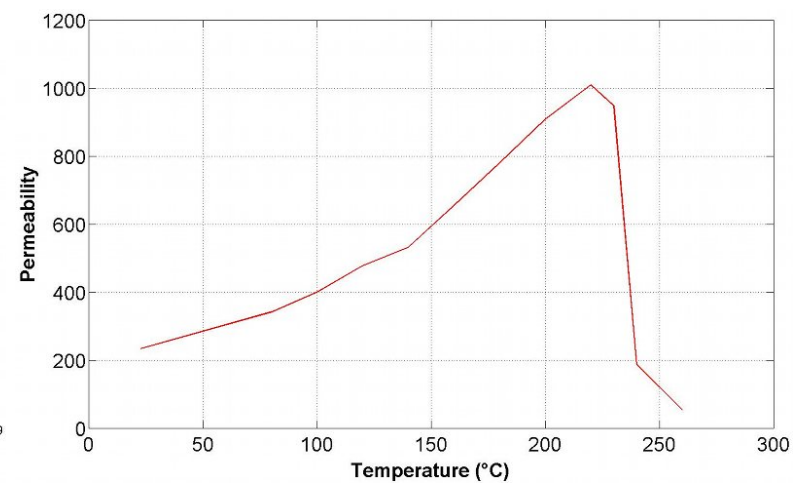

(b) $\mu_{R}^{\prime}$ change @ $100 \mathrm{kHz}$

Figure 7: Permeability characterization as function of temperature

\section{Inductor characterization}

As shown in the previous part, measurements show that material characteristics are affected by the temperature. However they are still usable, although with derated performances, at $200{ }^{\circ} \mathrm{C}$. This part will present the global inductor behavior with temperature increase.

\section{Test bench description and validation}

Inductance measurements with a probe as depicted in figure 8(a) are only possible at ambient temperature.

A dedicated test board is required in order to evaluate the influence of the temperature on the inductance value and to keep the probe away from the heat source. The micro-inductor under test is bonded on high 
temperature printed copper board as shown in figure 8(b). As described before, the inductor under test is heated using a hot air flow. Two similar boards are used to de-embed the board parasitics. This test bench and the measurement protocol (including compensation of parasitics) are evaluated using a coreless inductor with identical geometric characteristics (Table I). This test allows comparing both measurements (probe and board) with the analytical calculation from Wheeler's formula (equation 3) [11]. As depicted in figure 9, both measurements match the theoretical results up to $10 \mathrm{MHz}$ and validate the test bench.

$$
L(n H)=K_{1} \cdot \mu_{0} \cdot \frac{N^{2} \cdot d_{\text {avg }}}{1+K_{2} \cdot \rho}=80 n H \quad \rho=\frac{d_{\text {out }}-d_{\text {in }}}{d_{\text {out }}+d_{\text {in }}} \quad K_{1}=2.34 \quad K_{2}=2.75
$$

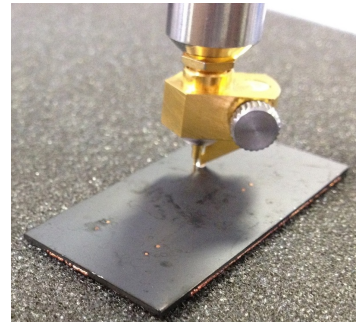

(a)

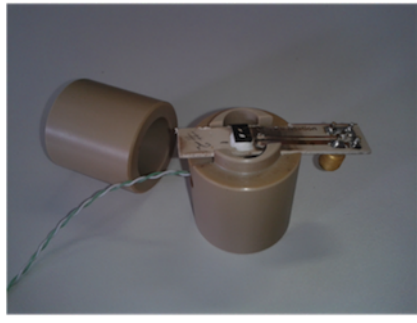

(b)

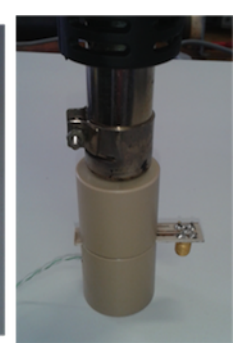

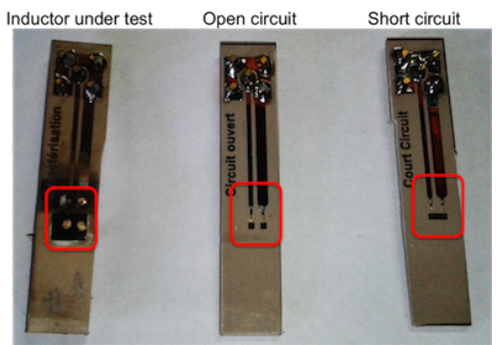

(c)

Figure 8: Test boards for inductor characterization

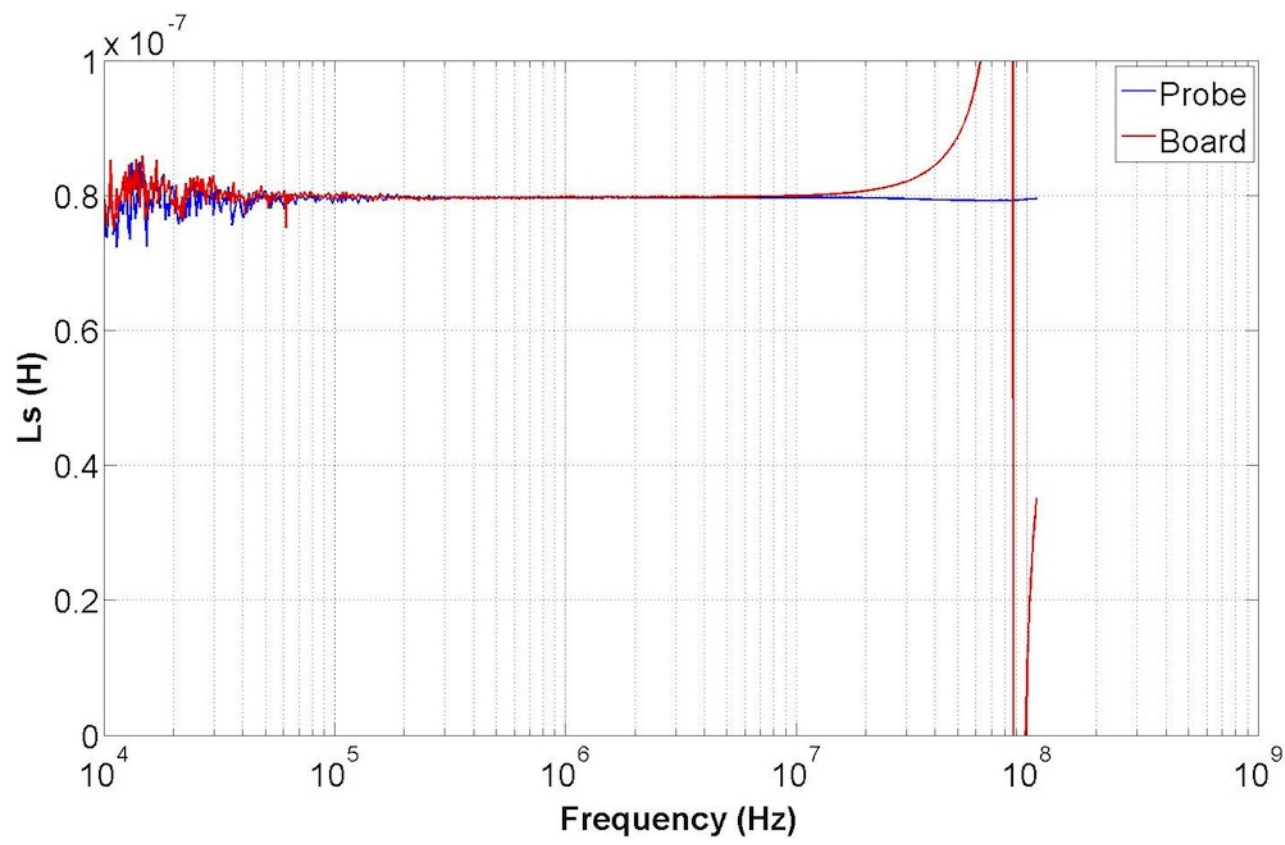

Figure 9: Measurement protocol validation

\section{Results and discussion}

Measurements are carried out on an inductor with a single magnetic layer as well as on an inductor with double magnetic material layers as depicted in figure 2.

The DC resistance is measured $(180 \mathrm{~m} \Omega)$ using the test bench described in figure 3 . The impedance measurements are performed from $10 \mathrm{kHz}$ to $110 \mathrm{MHz}$ using the HP4294A impedance analyzer. Figure 10 depicts the inductance variation over the frequency range. The inductance value is three times higher 
with 2 magnetic material layers compared to a single magnetic layer. The inductance value decrease starts at 2-3 MHz. This trend is consistent with the evolution of the real part of the complex permeability in figure 5(a).

Figure 11(a) represents the behavior of the inductor in the frequency range studied for different temperatures $\left(23^{\circ} \mathrm{C}\right.$ to $\left.260{ }^{\circ} \mathrm{C}\right)$. According to the permeability change observed in figure $7(\mathrm{a})$, the inductance value is more affected in low frequency range. Assuming that the temperature is below the Curie temperature of the magnetic material, the inductance value remains constant with temperature beyond $1 \mathrm{MHz}$. Figure 11(b) represents the inductance value change with temperature at $100 \mathrm{kHz}$. The inductance value doubles as the temperature increases from $23{ }^{\circ} \mathrm{C}$ to $230{ }^{\circ} \mathrm{C}$. Above $230{ }^{\circ} \mathrm{C}$, the inductance value drops in compliance with the permeability variation of the magnetic material.

As a consequence, and even if the inductor can be used up to $230{ }^{\circ} \mathrm{C}$, its operating temperature should be limited below $200{ }^{\circ} \mathrm{C}$ to provide some safety margins. Furthermore, self-heating could also cause a temperature rise of the magnetic core which must be taken into account in the converter design.

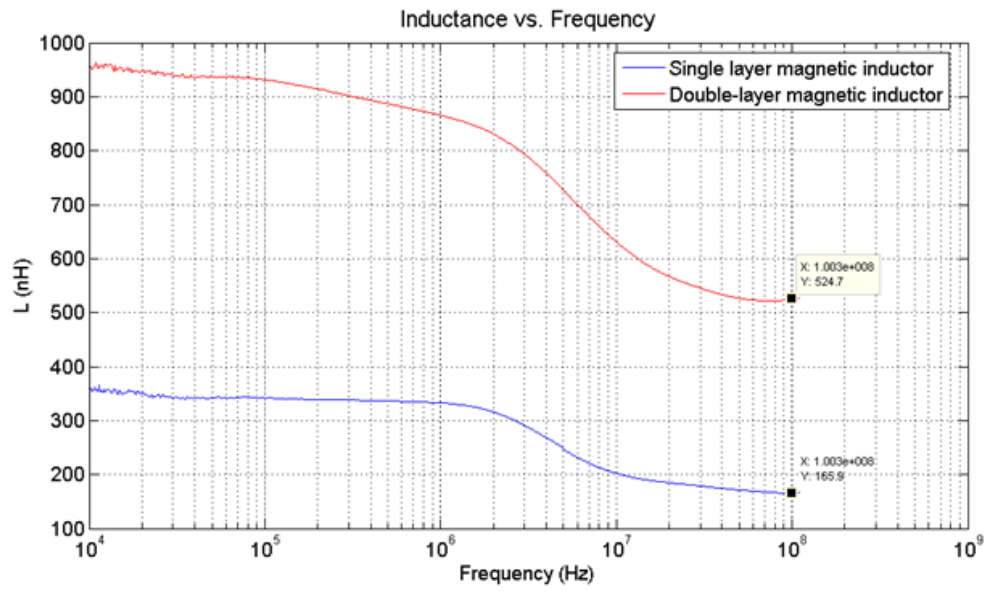

Figure 10: Inductance variation of a single layer magnetic inductor (red line) and a double-layer magnetic inductor (blue line)

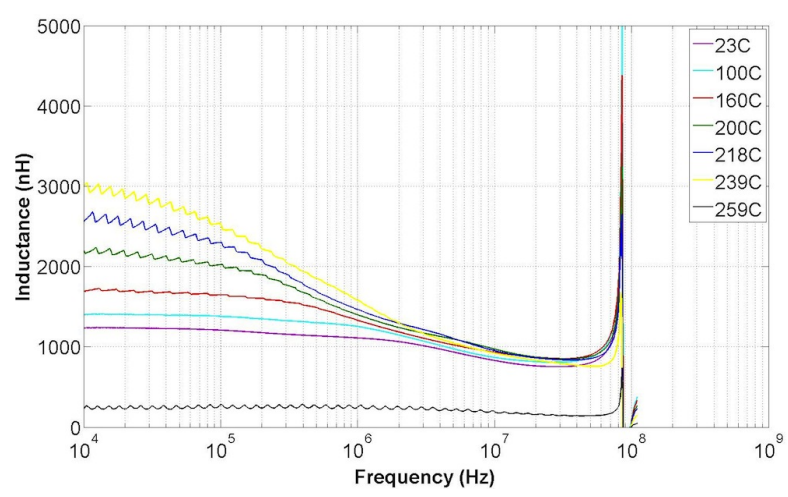

(a) Inductance variation

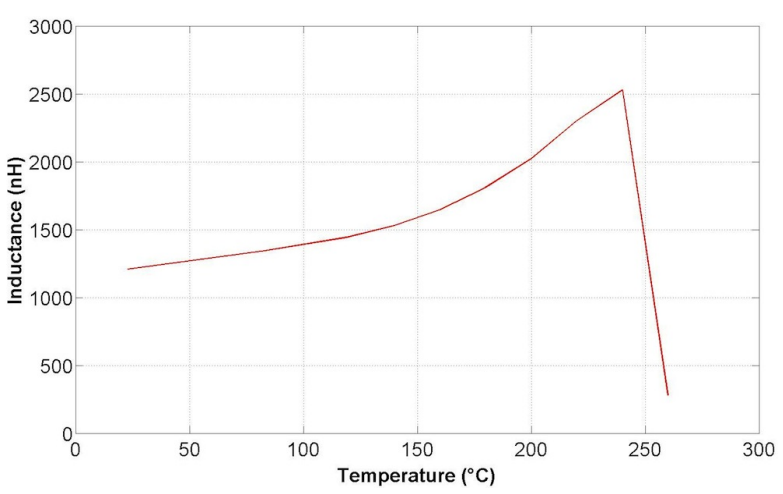

(b) Inductance variation @ $100 \mathrm{kHz}$

Figure 11: Inductance variation in $23{ }^{\circ} \mathrm{C}$ to $260{ }^{\circ} \mathrm{C}$ temperature range 


\section{Conclusion}

The fabrication process of micro-inductors were presented. Materials were chosen with respect to their electrical and thermal characteristics in order to withstand high temperature operating conditions $\left(200{ }^{\circ} \mathrm{C}\right)$. Test benches were described for the characterization of both materials and inductors. All characterizations have been performed from $25{ }^{\circ} \mathrm{C}$ to $260{ }^{\circ} \mathrm{C}$. These tests highlight the influence of the magnetic material on the inductor performances. Future works consist of testing the micro-inductors in DC-DC converters in order to evaluate DC current bias and temperature effects.

\section{References}

[1] M. W. Trifon Liakopoulos, Amrit Panda and A. Lotfi, "Manufacturing development of a new electroplated magnetic alloy enabling commercialization of pwrsoc products," IEEE PowerSoC 2012 - Third International Workshop on Power Supply on Chip, November 2012.

[2] M. Bathily, B. Allard, F. Hasbani, V. Pinon, and J. Verdier, "Design flow for high switching frequency and large-bandwidth analog DC/DC step-down converters for a polar transmitter," Power Electronics, IEEE Transactions on, vol. 27, no. 2, pp. 838 -847, feb. 2012.

[3] H. Bergveld, K. Nowak, R. Karadi, S. Iochem, J. Ferreira, S. Ledain, E. Pieraerts, and M. Pommier, "A 65-nm-CMOS 100-MHz 87\%efficient dc-dc down converter based on dual-die system-in-package integration," in Energy Conversion Congress and Exposition, 2009. ECCE 2009. IEEE, sept. 2009, pp. $3698-3705$.

[4] C. Mathúna, N. Wang, S. Kulkarni, and S. Roy, "Review of integrated magnetics for power supply on chip (pwrsoc)," Power Electronics, IEEE Transactions on, vol. 27, no. 11, pp. 4799-4816, 2012.

[5] R. Robutel, C. Martin, H. Morel, C. Buttay, N. Gazel, and D. Bergogne, "Design of a High Temperature EMI Input Filter for a 2 kW HVDC-Fed Inverter," Journal of Microelectronics and Electronic Packaging, vol. 8, no. 1, pp. 23-30, 2011. [Online]. Available: http://hal.archives-ouvertes.fr/hal-00729066

[6] E. Haddad, C. Martin, B. Allard, C. Joubert, M. Soueidan, M. Lazar, and B. Gervet, "Modeling, fabrication, and characterization of planar inductors on yig substrates," Advanced materials research, vol. 324, pp. 294-297, 2011.

[7] L. Ménager, "Contribution à l'intégration des convertisseurs de puissance en 3D," Ph.D. dissertation, Institut National des Sciences Appliquées de Lyon, 2008.

[8] A. Reeves, Introduction to elecrodynamics. David Griffiths, 1999, ch. 7, p. 286.

[9] H. Y. Lu, J. G. Zhu, and S. Hui, "Measurement and modeling of thermal effects on magnetic hysteresis of soft ferrites," Magnetics, IEEE Transactions on, vol. 43, no. 11, pp. 3952 -3960, nov. 2007.

[10] K. Arai, M. Yamaguchi, H. Ohzeki, and M. Matsumoto, "Application of yig film to thin film inductors," Magnetics, IEEE Transactions on, vol. 27, no. 6, pp. $5337-5339$, nov 1991.

[11] S. Mohan, M. del Mar Hershenson, S. Boyd, and T. Lee, "Simple accurate expressions for planar spiral inductances," Solid-State Circuits, IEEE Journal of, vol. 34, no. 10, pp. 1419-1424, 1999. 